\title{
A Practical Approach to the Treatment of Low-Risk Childhood Fever
}

\author{
Dipak Kanabar
}

Published online: 12 June 2014

(C) The Author(s) 2014. This article is published with open access at Springerlink.com

\begin{abstract}
Fever is a common symptom of childhood infections that in itself does not require treatment. The UK's National Institute for Health and Care Excellence (NICE) advises home-based antipyretic treatment for lowrisk feverish children only if the child appears distressed. The recommended antipyretics are ibuprofen or paracetamol (acetaminophen). They are equally recommended for the distressed, feverish child; therefore, healthcare professionals, parents and caregivers need to decide which of these agents to administer if the child is distressed. This narrative literature review examines recent data on ibuprofen and paracetamol in feverish children to determine any clinically relevant differences between these agents. The data suggest that these agents have similar safety profiles in this setting and in the absence of underlying health issues, ibuprofen seems to be more effective than paracetamol at reducing NICE's treatment criterion, 'distress' (as assessed by discomfort levels, symptom relief, and general behavior).
\end{abstract}

D. Kanabar $(\bowtie)$

Evelina London Children's Hospital, St Thomas' Hospital,

Westminster Bridge Road, London SE1 7EH, UK

e-mail: dkanabar@doctors.org.uk

\section{Key Points}

Clinical data suggest that ibuprofen and paracetamol have similar safety profiles but underlying health issues need to be considered when choosing between the two antipyretics to treat a feverish, distressed child

Studies suggest that ibuprofen is more effective than paracetamol at relieving fever-associated discomfort, providing symptom relief and improving general behavior

Selecting the most suitable antipyretic for the individual child may help to optimize the chance of treatment success first time, thereby limiting the need to administer further treatment

\section{Introduction}

Fever is the primary presentation for a host of childhood illnesses, and its underlying cause is generally benign. Fever may have a beneficial effect in terms of fighting infection [1], although its value in the recovery process is far from clear, since in vivo data are largely lacking. Fever can, however, be associated with distress and discomfort in children, leading to a high degree of parental concern. For febrile children without any indication of a serious underlying condition ('low-risk' fever), national guidelines recommend home management [1-4]. However, despite the recognition over 30 years ago of parental misconceptions around childhood fever and calls for improved educational intervention, 'fever phobia' remains common, and parents 
and caregivers continue to show uncertainty, misjudgment and anxiety in managing their feverish child [5-7].

Recently, the UK's National Institute for Health and Care Excellence (NICE) issued guidelines for the assessment and initial treatment of the feverish child, an update of earlier guidelines produced in 2007 [2]. NICE defines fever as an elevation of body temperature above the normal daily variation. For the assessment of children with fever, NICE has developed the 'traffic light' system for identifying the risk of a serious illness such as meningitis (Table 1). Children who have all the green (low-risk) features and no amber (intermediate-risk) or red (high-risk) features are most likely to have a self-limiting viral infection, and can be cared for at home with appropriate advice provided to parents and caregivers. Key among the updated recommendations is the advice to treat with an antipyretic only if the child appears distressed, with a focus on comforting the child, rather than on achieving normothermia (Table 2). In line with evidence showing increased discomfort and a lack of efficacy relative to antipyretics [810], physical interventions such as tepid sponging are no longer recommended for the treatment of fever [2].

Management of the distressed, feverish child therefore relies on the use of drug intervention and both ibuprofen and paracetamol (acetaminophen) are given equal status in the current guidelines. Parents and caregivers therefore need to choose between the two, the key aspects of which are compared in Table 3, and may seek guidance from healthcare professionals (HCPs) as to which is more appropriate for their child.

Interestingly, despite equal recommendation in guidelines, there is evidence to suggest that paracetamol is the

Table 1 NICE guidelines for identifying low-risk, intermediate-risk and high-risk fever in children [2]

\begin{tabular}{|c|c|c|c|}
\hline & Green/low risk & Amber/intermediate risk & Red/high risk \\
\hline $\begin{array}{l}\text { Color (of skin, lips or } \\
\text { tongue) }\end{array}$ & Normal color & Pallor reported by parent/carer & Pale/mottled/ashen/blue \\
\hline Activity & $\begin{array}{l}\text { Responds normally to social cues } \\
\text { Content/smiles } \\
\text { Stays awake or awakens quickly } \\
\text { Strong normal cry/not crying }\end{array}$ & $\begin{array}{l}\text { Not responding normally to social } \\
\text { cues } \\
\text { No smile } \\
\text { Wakes only with prolonged } \\
\text { stimulation } \\
\text { Decreased activity }\end{array}$ & $\begin{array}{l}\text { No response to social cues } \\
\text { Appears ill to a healthcare } \\
\text { professional } \\
\text { Does not wake or if roused does not } \\
\text { stay awake } \\
\text { Weak, high-pitched or continuous cry }\end{array}$ \\
\hline Respiratory & & $\begin{array}{l}\text { Nasal flaring } \\
\text { Tachypnea: respiratory rate } \\
>50 \text { breaths/minute, age } \\
6-12 \text { months } \\
>40 \text { breaths/minute, age }>12 \text { months } \\
\text { Oxygen saturation } \leq 95 \% \text { in air } \\
\text { Crackles in the chest }\end{array}$ & $\begin{array}{l}\text { Grunting } \\
\text { Tachypnea: respiratory rate }>60 \\
\text { breaths/minute } \\
\text { Moderate or severe chest indrawing }\end{array}$ \\
\hline $\begin{array}{l}\text { Circulation and } \\
\text { hydration }\end{array}$ & $\begin{array}{l}\text { Normal skin and eyes } \\
\text { Moist mucous membranes }\end{array}$ & $\begin{array}{l}\text { Tachycardia: } \\
>160 \text { beats/minute, age }<12 \text { months } \\
>150 \text { beats/minute, age } \\
12-24 \text { months } \\
>140 \text { beats/minute, age } 2-5 \text { years } \\
\text { Capillary refill time } \geq 3 \text { seconds } \\
\text { Dry mucous membranes } \\
\text { Poor feeding in infants } \\
\text { Reduced urine output }\end{array}$ & Reduced skin turgor \\
\hline Other & $\begin{array}{l}\text { None of the amber or red symptoms } \\
\text { or signs }\end{array}$ & $\begin{array}{l}\text { Age } 3-6 \text { months and temperature } \\
\geq 39{ }^{\circ} \mathrm{C} \\
\text { Fever for } \geq 5 \text { days } \\
\text { Rigors } \\
\text { Swelling of a limb or joint } \\
\text { Non-weight bearing limb/not using an } \\
\text { extremity }\end{array}$ & $\begin{array}{l}\text { Age }<3 \text { months and temperature } \\
\quad \geq 38{ }^{\circ} \mathrm{C} \\
\text { Non-blanching rash } \\
\text { Bulging fontanelle } \\
\text { Neck stiffness } \\
\text { Status epilepticus } \\
\text { Focal neurological signs } \\
\text { Focal seizures }\end{array}$ \\
\hline
\end{tabular}

NICE National Institute for Health and Care Excellence 
Table 2 NICE guidelines for antipyretic interventions in children [2]

Antipyretic agents do not prevent febrile convulsions and should not be used specifically for this purpose

Tepid sponging is not recommended for the treatment of fever

Children with fever should not be underdressed or over-wrapped

Consider using either paracetamol or ibuprofen in children with fever who appear distressed

Do not use antipyretic agents with the sole aim of reducing body temperature in children with fever

When using paracetamol or ibuprofen in children with fever:

Continue only as long as the child appears distressed

Consider changing to the other agent if the child's distress is not alleviated

Do not give both agents simultaneously

Only consider alternating these agents if the distress persists or recurs before the next dose is due

NICE National Institute for Health and Care Excellence

Table 3 Summary of over-the-counter (OTC) paracetamol and ibuprofen for the distressed, feverish child

\begin{tabular}{|c|c|c|}
\hline & Paracetamol & Ibuprofen \\
\hline $\begin{array}{l}\text { Typical OTC dosing } \\
\text { interval }\end{array}$ & 4 hours & 6 hours \\
\hline $\begin{array}{l}\text { Route of OTC } \\
\text { administration }^{\text {a }}\end{array}$ & Oral, palatable suspension is available & Oral, palatable suspension is available \\
\hline Commercial availability & $\begin{array}{l}\text { Brands such as Calpol and Tylenol are established } \\
\text { and familiar to parents }\end{array}$ & $\begin{array}{l}\text { Potentially less familiarity with brands such as Nurofen for } \\
\text { Children }\end{array}$ \\
\hline Efficacy & Effective [2] & $\begin{array}{l}\text { Effective [2]. Better than paracetamol at reducing fever- } \\
\text { related discomfort }[26,27]\end{array}$ \\
\hline \multirow[t]{6}{*}{$\begin{array}{l}\text { Safety considerations } \\
\text { relevant to specific } \\
\text { patient groups }\end{array}$} & $\begin{array}{l}\text { May be preferable for children with gastrointestinal } \\
\text { infection }\end{array}$ & $\begin{array}{l}\text { Risk of gastrointestinal irritation [35], true incidence } \\
\text { uncertain due to under-reporting, short-term use may be } \\
\text { asymptomatic }\end{array}$ \\
\hline & $\begin{array}{l}\text { May be preferable in patients at high risk of } \\
\text { gastrointestinal bleeding }\end{array}$ & $\begin{array}{l}\text { Risk of gastrointestinal bleeding_-potentially serious, but } \\
\text { rare. No significant difference in risk from paracetamol [1, } \\
40,41]\end{array}$ \\
\hline & $\begin{array}{l}\text { Increased risk of asthma-related outpatient } \\
\text { attendance in children with asthma [49] }\end{array}$ & $\begin{array}{l}\text { May be preferable for children with asthma (but without } \\
\text { aspirin-sensitive asthma) }\end{array}$ \\
\hline & May be preferable for children with chicken pox & $\begin{array}{l}\text { Risk of severe cutaneous complications in patients with } \\
\text { varicella or herpes zoster [77] }\end{array}$ \\
\hline & $\begin{array}{l}\text { Risk of hepatotoxicity-potentially serious, but rare } \\
{[1,88]}\end{array}$ & $\begin{array}{l}\text { May be preferable where there is a risk of dosing error or } \\
\text { confusion }\end{array}$ \\
\hline & $\begin{array}{l}\text { May be preferable for children who are dehydrated } \\
\text { or with pre-existing renal disease or multi-organ } \\
\text { failure }\end{array}$ & Risk of renal toxicity_potentially serious, but rare [1] \\
\hline
\end{tabular}

${ }^{a}$ Different routes of administration may be used for pediatric fever in hospitalized patients

'favored' antipyretic medication for home management of pediatric fever [11]. The reasons for this apparent discrepancy are unclear, although over-the-counter (OTC) paracetamol has been available for longer than ibuprofen, and brand names such as Calpol and Tylenol are consequently firmly established in the minds of parents. This familiarity can present advantages (rapid access when required) and disadvantages (resistance to change). There may also be perceptions, for both parents and HCPs, around relative safety and efficacy. This narrative literature review of recent data aims to determine whether there are any clinically relevant differences in efficacy and safety between ibuprofen and paracetamol that may recommend one agent over the other in the management of the distressed, feverish child. In addition, it also explores why there is a discrepancy between current guidelines and the real-world use of these treatments.

\section{To Treat or Not to Treat}

Before discussing treatment, it is important to consider what constitutes 'distress' and how parents interpret this term [12]. Perception of distress is likely to vary markedly between parents, and may be linked to factors such as level of education, socioeconomic status and cultural 
background [13-15]. This may impact on when a parent decides to start treating their child with an antipyretic, whether to change antipyretics, or indeed when to consult an HCP. The problem of defining distress is recognized in the NICE guidelines, and the Guideline Development Group has called for studies on home-based antipyretic use and parental perception of distress caused by fever in order to clarify issues such as triggers for antipyretic use and help-seeking behavior [2].

The rationale for treating only the distressed, feverish child is based on the fact that absolute body temperature alone does not appear to be an indicator of serious infection $[16,17]$. In addition, there is no evidence that fever in itself increases the risk of parentally-feared adverse events such as febrile convulsions or brain damage [18], and lowering temperature with antipyretics does not appear to be effective at preventing febrile convulsions [19,20]. Based on such data, recent guidelines emphasize the need to treat only the symptoms of fever in children who are either in discomfort or distressed, and not to focus on normothermia [1-3]. Despite this, an elevated body temperature (whatever site or method of measurement is used), even below $38{ }^{\circ} \mathrm{C}$, continues to be a cause of concern for many parents [7]. Unfounded concerns contribute to reports that the vast majority of caregivers would give antipyretic medication to a feverish child, even if the child appeared otherwise comfortable [7, 13, 21]. Overall, it seems that parental misconceptions around fever and 'fever phobia' have changed little since this problem was first recognized over 30 years ago [6]. Overcoming such concerns and gaining parental acceptance of current recommendations not to give antipyretics simply to reduce fever in children, but only to alleviate distress [2, 22], is clearly a major challenge.

\section{Treating the Distressed, Feverish Child}

While reduction of fever should not be the primary indication for antipyretic treatment according to NICE guidelines, when a child is distressed, treatment with antipyretics is likely to ease symptoms. The distress experienced by feverish children may in fact be due to the mismatch in body and environmental temperatures, as well as any illness-associated pain. It is clear to see why alleviating these symptoms could reduce the distress associated with fever.

\subsection{Fever Reduction}

Despite recommendations to treat distress rather than fever, 'fever phobia' means that fever itself is currently the target of therapy for many parents, with a rapid and prolonged effect being their likely priority for comforting their child and to minimize medication. Overall, meta-analyses suggest that ibuprofen provides more rapid and longer lasting fever reduction in children compared with paracetamol [23-25]. In a large, randomized, blinded study of paracetamol plus ibuprofen for the treatment of fever in children $(\mathrm{PITCH})$, involving 156 children who were being managed at home, ibuprofen was shown to provide faster fever clearance and longer time without fever in the first 24 hours compared with paracetamol [26].

\subsection{Symptomatic Relief}

Given that the NICE guidelines do not recommend the use of antipyretic treatment solely to reduce temperature, the primary consideration in antipyretic choice should be relief of distress (i.e., the recommended indications for antipyretic use in childhood fever). Subjective assessments such as how uncomfortable or distressed a child appears are clearly less easy to quantify than temperature reduction; nevertheless, they have been assessed in a number of studies. The PITCH study found that treatment with ibuprofen led to a greater number of children being recorded as having no discomfort at 24 hours $(69 \%$ vs $44 \%$ for paracetamol) (Fig. 1) [26]. Based on such findings, the authors of the PITCH study recommended that ibuprofen should be used as first-line therapy in feverish children [11, 26].

The findings of the PITCH study are in line with an earlier study which also reported that comfort (assessed on scores of general behavior and degree of relief) was higher with ibuprofen compared with paracetamol [27]. Interestingly, in a study by Autret-Leca and colleagues [28], significantly more parents of children treated with ibuprofen rated the drug as 'very efficacious' compared with parents of children treated with paracetamol, despite the fact that there was no measurable difference in antipyretic efficacy (area under the temperature reduction curve expressed as an absolute difference from baseline, from 0 to $6 \mathrm{~h}$ )

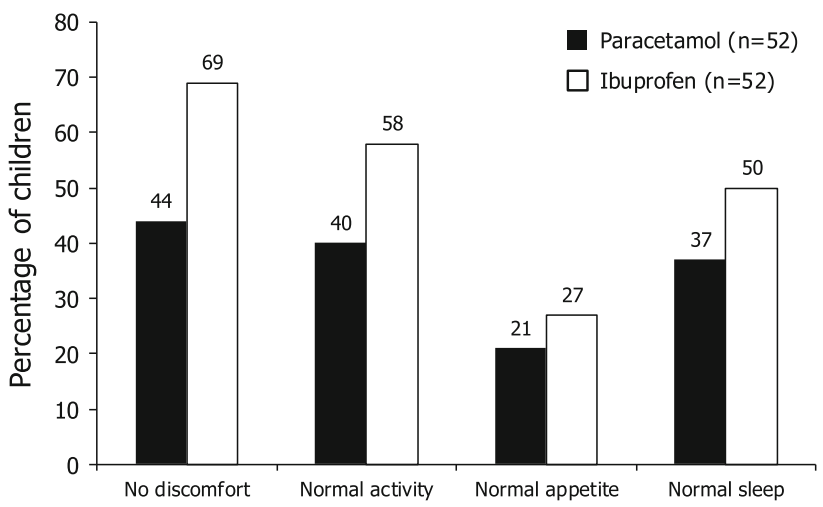

Fig. 1 Percentage of children without fever-associated symptoms at 24 hours (the PITCH study) [26] 
between ibuprofen and paracetamol. This suggests that the superiority of ibuprofen in terms of symptom relief may be related to additional benefits other than simply temperature reduction. For example, ibuprofen has been shown to be more effective than paracetamol for pediatric pain relief in several studies in different settings [29-31] and in a recent meta-analysis [25], suggesting that pain may be an important contributory factor to a child's overall discomfort when suffering from the effects of a febrile illness.

\subsection{Efficacy: Summary}

Based on available data, ibuprofen appears to have a more rapid onset and longer duration of effect, and provides more effective relief of fever-associated discomfort compared with paracetamol, particularly in the first 24 hours of the child's illness. Rapid relief of symptoms is clearly an important consideration in feverish children; a child who is comfortable is more likely to maintain nutrition and hydration, for example. In addition, the longer duration of action of ibuprofen may also improve sleep patterns [32]. Taken together, rapid and prolonged symptomatic relief not only has benefits for the child, but also for the wider family.

\subsection{Safety}

Safety is clearly a primary consideration in the choice of antipyretic. Overall, ibuprofen and paracetamol are considered to have similar safety and tolerability profiles in pediatric fever, and this has been confirmed in meta-analyses [25, 33]. For example, a recent meta-analysis including 19 evaluable studies found no significant difference between the two agents in terms of the incidence of adverse events in pediatric patients (odds ratio [OR] 0.82; $95 \%$ confidence interval [CI] 0.60-1.12) [25]. Larger studies are, however, required to adequately detect and quantify rare adverse effects.

Ibuprofen and paracetamol are considered to be generally well tolerated by children [34]; however, a number of specific safety issues are often raised for both agents which may impact on recommendations and prescribing practice. The question arises as to whether these concerns are evidence-based, or have arisen due to medical 'myths' or 'dogma'.

\subsubsection{Gastrointestinal Effects}

Concerns regarding potential adverse gastrointestinal (GI) effects with the use of non-steroidal anti-inflammatory drugs (NSAIDs) are relatively common. While GI bleeding is the most serious, GI irritation may be a more frequent adverse event [35], although its true incidence is uncertain since many mild cases are likely to go unreported. In a double-blind study of children taking ibuprofen $(n=76)$ or paracetamol $(n=74)$ for up to 3 days, there was only one GI event (diarrhea) reported as possibly related to treatment, and this occurred in the ibuprofen group [36]. Potentially, GI irritation could be important in the setting of a GI infection since there is synergism for the development of peptic ulcers and ulcer bleeding between Helicobacter pylori infection and NSAID use [37]. However, as discussed below, clinical data suggest that-for short-term use such as pediatric fever-related symptoms, and with doses available OTC - the risk of GI events is no greater for NSAIDs than for paracetamol.

Dose-dependent GI toxicity (e.g., bleeding) in association with NSAID treatment in adults is well documented in 'at-risk' patients [38]. However, at OTC doses in adults, symptomatic GI side effects with ibuprofen are comparable with placebo and treatment is well tolerated [38].

Whilst there are less data regarding GI effects in febrile children, in one of the largest trials comparing ibuprofen and paracetamol use, the risk of GI bleeding was low (7.2 per 100,000 for ibuprofen and 0 per 100,000 for paracetamol), with no statistically significant difference between the two treatment groups $(p=0.31)$ [39]. The four cases of GI bleeding reported in this study occurred in children treated with ibuprofen, all of whom were managed conservatively with no endoscopy being required [39]. This finding is occasionally cited as a potential cause for concern, despite the lack of significance relative to paracetamol. However, since this early study, other studies have confirmed that upper GI complications (UGICs) are rare events in children treated with NSAIDs, with a low absolute risk [40, 41]. In addition, a recent case-controlled study in children admitted to hospital via emergency departments for acute conditions over an 11-year period found no significant difference in risk of UGICs with paracetamol (adjusted OR 2.0; $95 \%$ CI 1.5-2.6) compared with ibuprofen (adjusted OR 3.7; $95 \%$ CI 2.3-5.9) [41].

One result of the perceived association of NSAIDs and UGICs is the common advice to take ibuprofen with food (or fluids such as milk), the rationale being that such coadministration exerts a 'protective' effect in the GI tract. Respectively, food and fluids also guard against glutathione depletion (and the attendant risk for hepatic toxicity) [42] and dehydration (and the attendant risk for renal toxicity) [43]. This has a particular impact for OTC use in childhood fever, where children may feel too unwell to eat or drink. As discussed in a recent literature review, the effect of fasting on NSAID-related GI effects has never been properly studied in humans [44]. Food is known to delay the achievement of peak levels of NSAIDs and so impacts on efficacy. Therefore, the authors suggested that it may be 
more appropriate to advocate OTC ibuprofen be taken on a fasting stomach in order to achieve a rapid onset of action and effect, thereby avoiding the use of an 'extra' dose [44].

\subsubsection{Asthma}

Aspirin-induced asthma is a well recognized clinical syndrome, arising most commonly in adults, and infrequently in children [45], and thought to be related to COX inhibition, which shows a high level of cross-sensitivity with other NSAIDs [46, 47]. A randomized, double-blind, placebo-controlled study found that ibuprofen-induced bronchospasm occurred in $2 \%$ of pediatric patients with asthma with a further $2 \%$ demonstrating a clinical decrease in spirometric measurements [48].

Ibuprofen does not appear to exacerbate asthma in children without a history of aspirin sensitivity, and may in fact be associated with a lower risk of exacerbation than paracetamol [47]. In two large studies of febrile children $[36,49]$, the unexpected finding was a slightly reduced risk of asthma compared with paracetamol usage. In one of these studies, a randomized controlled trial in febrile children with asthma, those who received ibuprofen were significantly less likely to require outpatient visits for asthma $3.0 \%$ for ibuprofen vs $5.1 \%$ for paracetamol; relative risk $0.56,95 \%$ CI $0.34-0.95)$ compared with children who received paracetamol [49]. Paracetamol use during pregnancy has been implicated in asthma development and the increasing incidence of asthma in adults and children in epidemiologic, observational and pathophysiologic studies (reviewed in [50-52] and more recently in a prospective birth cohort study [53]). Given the widespread use of paracetamol in children, there has been a call for causation to be proved or disproved in adequately powered placebo-controlled trials [54], and clearly more research is required in this field.

\subsubsection{Renal Effects}

NSAIDs have been associated with the development of acute kidney injury (AKI), which is thought to be related to a reduction in prostaglandin synthesis [55], which is required for renal perfusion in dehydration [56]. This is a potentially serious, albeit rare, adverse effect associated with NSAID use. There were no incidences of acute renal failure in a large practitioner-based population study which included 55,785 children treated with ibuprofen [39], or in the Boston Collaborative Fever study which included 27,065 febrile children randomized to ibuprofen [57]. A further study by the same authors found that, with shortterm use of ibuprofen, the risk of less severe renal impairment is small and not significantly greater than with paracetamol [58].
Similarly, a large-scale pediatric study by Ashraf and colleagues [59] found no incidences of renal conditions in over 30,000 children treated with either ibuprofen or paracetamol. There have, however, been rare case reports of reversible renal insufficiency in children with febrile illness treated with ibuprofen or other NSAIDs, largely associated with volume depletion [60-62]. Dehydration is common in children with fever [63] and is an important risk factor for NSAID-induced acute renal failure; this has led some experts to recommend caution with ibuprofen use in children with dehydration or pre-existing renal disease [1, 22]. Recently, a retrospective chart review of 1,015 children with AKI managed over an 11.5-year period concluded that 27 cases $(2.7 \%)$ were associated with NSAID use (predominantly ibuprofen), and that younger children $(<5$ years of age $)$ were more likely to require dialysis or admission into intensive care units [64]. This retrospective study raises obvious concerns; however, it has a number of limitations. Most importantly, patients with a history of volume depletion, an independent risk factor for AKI, were not excluded from the analysis. The most common presenting symptoms in this study were vomiting and decreased urine output, and the majority of children defined as having NSAID-associated AKI had a history of volume depletion. One possibility is that these dehydrated patients may have developed AKI independently of NSAID use.

In clinical practice, the author's experience is that renal problems arising out of short-term usage of ibuprofen in feverish children are an unlikely occurrence; nevertheless, caution (and common sense) should be applied when administering any agent that may interfere with renal function in a child with volume depletion and/or multiorgan failure.

\subsubsection{Hepatotoxicity and Risk of Overdose}

Overdose of either drug can cause hepatotoxicity (which can be asymptomatic), although this is most often a risk linked with paracetamol. Hepatotoxicity is a potentially serious, albeit rare, adverse effect that has been reported with paracetamol in children at recommended doses [6567] as well as in the setting of an acute overdose [68, 69]. There is also the possibility of paracetamol-related hepatitis due to chronic overdose following either the administration of supratherapeutic doses or too frequent administration of appropriate single doses [1, 70]. Current UK dosing guidelines are age-based (Table 4). However, a recent UK study found that underweight children are at risk of receiving approximately $200 \%$, and average-weight children up to $133 \%$ of the recommended single and cumulative daily dose of paracetamol, leading to recently proposed changes in dosing recommendations [71, 72]. To reduce the risk of overdosing or underdosing, dosing 
Table 4 Standard over-the-counter (OTC) dose for paracetamol and ibuprofen

\begin{tabular}{|c|c|}
\hline Paracetamol & Ibuprofen \\
\hline $\begin{array}{l}\text { Age 2-3 months: } 60 \mathrm{mg} \text {, with a further } 60 \mathrm{mg} \text { after } 4-6 \text { hours if } \\
\text { necessary (maximum of two doses) [89] }\end{array}$ & $\begin{array}{l}\text { Age } 3-5 \text { months: } 50 \mathrm{mg} \text { three times a day (maximum of three doses in } \\
24 \text { hours, do not use for more than } 24 \text { hours) }\end{array}$ \\
\hline $\begin{array}{l}\text { Age } 3-6 \text { months: } 60 \mathrm{mg} \text { every } 4-6 \text { hours (maximum of four doses } \\
\text { in } 24 \text { hours) }\end{array}$ & Age 6 months to 1 year: $50 \mathrm{mg}$ three to four times a day \\
\hline $\begin{array}{l}\text { Age } 6-24 \text { months: } 120 \mathrm{mg} \text { every } 4-6 \text { hours (maximum of four } \\
\text { doses in } 24 \text { hours) }\end{array}$ & Age $1-4$ years: $100 \mathrm{mg}$ three times a day \\
\hline $\begin{array}{l}\text { Age } 2-4 \text { years: } 180 \mathrm{mg} \text { every } 4-6 \text { hours (maximum of four doses } \\
\text { in } 24 \text { hours) }\end{array}$ & Age 4-7 years: $150 \mathrm{mg}$ three times a day \\
\hline $\begin{array}{l}\text { Age } 4-6 \text { years: } 240 \mathrm{mg} \text { every } 4-6 \text { hours (maximum of four doses } \\
\text { in } 24 \text { hours) }\end{array}$ & Age $7-10$ years: $200 \mathrm{mg}$ three times a day \\
\hline $\begin{array}{l}\text { Age } 6-8 \text { years: } 250 \mathrm{mg} \text { every } 4-6 \text { hours (maximum of four doses } \\
\text { in } 24 \text { hours) }\end{array}$ & Age $10-12$ years: $300 \mathrm{mg}$ three times a day \\
\hline $\begin{array}{l}\text { Age } 8-10 \text { years: } 375 \mathrm{mg} \text { every } 4-6 \text { hours (maximum of four doses } \\
\text { in } 24 \text { hours) }\end{array}$ & Age $12-16$ years: 200 to $400 \mathrm{mg}$ three to four times a day \\
\hline $\begin{array}{l}\text { Age } 10-16 \text { years: } 500 \mathrm{mg} \text { every } 4-6 \text { hours (maximum of four } \\
\text { doses in } 24 \text { hours) }\end{array}$ & Source: [90] \\
\hline Source: [90] & \\
\hline
\end{tabular}

Higher doses and different routes of administration may be used for pediatric fever in hospitalized patients

guidelines in some other countries are based on weight or both age and weight; the typical recommendation for ibuprofen is $5-10 \mathrm{mg} / \mathrm{kg}$ per dose, while for paracetamol it is $10-15 \mathrm{mg} / \mathrm{kg}$ per dose [1, 22, 73].

Reports of complications following ibuprofen overdose, particularly in children, are rare. The vast majority of individuals who overdose on ibuprofen alone have no, or only mild, symptoms [74]. Fatal overdose in adults is extremely rare and is generally related to complicating factors such as the presence of other drugs. Cases of symptomatic overdose in children have been reported following ingestion of over $440 \mathrm{mg} / \mathrm{kg}$ [75], but in general the risk of serious complications following ibuprofen overdose is low [76].

\subsubsection{Other}

An increased risk of severe cutaneous complications in patients with varicella or herpes zoster has been reported for NSAIDs but not for paracetamol [77]. Consequently, it has been recommended that fever and pain associated with varicella or herpes zoster infection should be treated with paracetamol, not an NSAID [77].

\subsubsection{Safety: Summary}

Specific safety issues that are often cited for ibuprofen and paracetamol may be a consideration for specific patient populations, but for the average child with symptoms of distress related to low-risk fever (that is, in the absence of underlying health issues) they are of less concern.
Ibuprofen and paracetamol have similar safety and tolerability profiles when short-term OTC doses are used.

\subsection{Combination Therapy}

The use of combination therapy with either alternating or simultaneous use of ibuprofen and paracetamol in feverish children is controversial. In children, clinical trials have reported that alternating ibuprofen and paracetamol is more effective at reducing fever than either agent alone [11, 78, 79], but there are few data on fever-related symptoms or distress. Recent systematic reviews have concluded that there is little evidence of any significant benefit (or harm) from combined or alternating treatment compared with the use of either drug alone $[80,81]$ and, in their recent update, NICE concluded that there was little evidence in the community that alternating therapy improves distress. Alternating the two agents is therefore only recommended if both have been ineffective as standalone treatments [2], the proviso being how a parent defines 'ineffective'. Factors such as parental anxiety, poorly obtained or recorded temperatures, subjective assessment of level of discomfort or distress, and a lack of knowledge on the time to onset of antipyretic effect may contribute both to dosing more frequently than recommended and to a perceived lack of response to monotherapy, resulting in unnecessary (and potentially harmful) use of alternating therapy [15]. A further consideration regarding alternating treatment is the possibility of parental confusion, which may result in accidental overdose or underdosing $[15,82,83]$. While the recommended dosing interval for ibuprofen is 6 hours, it is 
4 hours for paracetamol, therefore a simple alternating dosing regimen can be difficult.

It is possible that treatment with a single combined dose of ibuprofen and paracetamol may offer a more effective option, with a reduced risk of dosing confusion compared with alternating therapy. There is a theoretical benefit to the co-administration of two antipyretics with different modes of action. Data in adults suggest that co-administration of ibuprofen and paracetamol provides highly effective pain relief [84] and antipyretic efficacy [85] (although distress was not measured in these patients), with a similar safety profile to each agent alone [86]. However, efficacy and safety data for combination therapy in children are lacking and, therefore, currently the author's recommendation would be that this practice is not suggested for general OTC usage, in agreement with the latest NICE recommendations.

\section{Summary and Conclusions}

The NICE guidelines give equal recommendation to the use of paracetamol or ibuprofen for the short-term treatment of distress in low-risk feverish children [2]. Therefore, the caregiver or HCP has to make a choice between these readily available OTC agents.

The aim of this review has been to compile and compare the efficacy and safety data from available clinical studies that directly compare ibuprofen and paracetamol such that any clinically relevant differences can be considered and sensible conclusions drawn as to whether one agent has advantage over the other, and to enable the caregiver (or HCP) to make an informed choice.

The age of the child can be a factor in the decision of which antipyretic to use, since paracetamol can be given at 2 months of age whereas ibuprofen has an OTC license in infants aged over 3 months (weight $>5 \mathrm{~kg}$ ) with a higher threshold of 6 months in some other countries, including the USA. However, from the age of 3 (or 6) months, both paracetamol and ibuprofen are suitable (Table 4).

Antipyretic efficacy data for ibuprofen and paracetamol are not relevant to the use of these agents in feverish children, considering the NICE guidance to focus on comforting the child, rather than on achieving normothermia. However, they do provide useful information. Antipyretic efficacy may indicate relevant pharmacologic onset and duration of effect, especially where distress is due to the mismatch in environmental and body temperatures. However, distress is likely multi-factorial so antipyretic efficacy cannot currently be used as a direct surrogate for efficacy against distress in feverish children; further research is required.

The evidence indicates that ibuprofen may provide greater relief of symptoms in the distressed, feverish child compared with paracetamol [26, 27]. The longer duration of action of ibuprofen means the number of doses can be kept to a minimum, and a single dose may be all that is required in certain circumstances (e.g., post-immunization pyrexia). In addition, the faster onset of action and greater symptomatic relief with ibuprofen means that the NICE recommendation to relieve distress can be achieved more rapidly, with the concomitant advantage of a faster return to 'normal' family life.

Meta-analyses confirm that the safety and tolerability profiles of paracetamol and ibuprofen in pediatric fever are similar [25, 33]. Both drugs are associated with specific rare adverse effects, which are difficult to detect and quantify in all but the largest clinical trials, and which may be relevant to specific patient populations. For example, ibuprofen may be preferable in the setting of asthma (without known aspirin sensitivity) or where there is a risk of the parent or caregiver experiencing confusion overdosing (and potentially overdosing the child), whilst paracetamol may be preferable when children have chicken pox, are dehydrated, have pre-existing renal disease or multi-organ failure, or are at increased risk of GI bleeding (Table 3). In reality, such children are likely to be under the care of a clinician, who is best placed to weigh up the risks and benefits of each drug for the individual patient.

Paracetamol is generally conceived by the public (or HCPs) as being a 'safer agent' with fewer adverse effects. Possible reasons to explain this misconception could include the earlier potential exposure to paracetamol (after the child's first immunization at 2 months of age), perhaps leading to a general misconception around its safety and tolerability. Therefore, with earlier familiarity, in the absence of advice to the contrary, many parents are likely to remain loyal to a drug they are used to. In addition, the fact that paracetamol is licensed for use in younger children may mean that parents perceive it to be a 'safer' medication. Familiarity also introduces risks, and the consequences of too frequent and unnecessary use of paracetamol can be serious. A further reason may be the often-cited advice to give ibuprofen with food (or milk), which could be associated with a perception of GI intolerability, despite the lack of evidence relating to short-term OTC usage.

While alternating treatment with ibuprofen and paracetamol may offer some advantages over monotherapy, a lack of efficacy and safety data in children, together with concerns around dosing confusion and risk of overdose, are currently considered to outweigh any benefit except in patients where single-agent treatment is ineffective.

The NICE guidelines recommend that children should only be treated for as long as symptoms persist; avoiding overtreatment is an important consideration with antipyretics, as with any drug. Conversely, delaying treatment or 
underdosing may result in unnecessary discomfort to a distressed, feverish child, and may affect their desire to eat or drink. Ongoing distress in febrile children may also impact parents and the wider family. Fears that antipyretic use may prolong febrile illness have been shown to be unfounded and there is there is little evidence to suggest that antipyretics mask the symptoms and signs of serious illness [87]. Encouraging the appropriate use of antipyretics in distressed, feverish children is therefore clearly important.

In conclusion, fever is a common symptom of childhood infection which in itself does not require treatment. However, fever in children can be distressing for all concerned and there is a need for improved education and healthcare advice so that parents and caregivers can confidently and effectively manage a child's low-grade fever at home. This includes being aware of the choice of OTC antipyretics available to them, knowing when to treat with an antipyretic agent, and being well informed on which agent to choose. The long-term goal of childhood fever management is improved self-care/home-care plans, with the advice and help of local pharmacists. This approach will help to empower parents and caregivers, enabling them to make informed decisions about their child's wellbeing rather than relying on general practitioners or emergency departments. NICE guidelines recommend treatment when dealing with a distressed, feverish child, with the focus on comforting the child rather than reducing the temperature. Whilst the guidelines do not recommend one agent over another, evidence presented in this paper suggests that ibuprofen may provide greater efficacy in terms of the relief of symptoms in the distressed, feverish child and that short-term OTC ibuprofen and paracetamol have similar safety and tolerability profiles, although each may be preferred in some specific patient populations.

Acknowledgements The author has received consultancy fees from Reckitt Benckiser Healthcare Ltd (Slough, UK) for participation in advisory board meetings. Editorial assistance for this manuscript was provided by Elements Communications Ltd (Westerham, UK) and funded by Reckitt Benckiser Healthcare Ltd (Slough, UK).

Open Access This article is distributed under the terms of the Creative Commons Attribution Noncommercial License which permits any noncommercial use, distribution, and reproduction in any medium, provided the original author(s) and the source are credited.

\section{References}

1. Sullivan JE, Farrar HC. Fever and antipyretic use in children. Pediatrics. 2011;127:580-7.

2. National Institute for Health and Care Excellence (NICE). Feverish illness in children, NICE clinical guideline 160. 2013. http://guidance.nice.org.uk/CG160 Accessed May 2014.
3. Chiappini E, Venturini E, Principi N, et al. Update of the 2009 Italian Pediatric Society Guidelines about management of fever in children. Clin Ther. 2012;34:1648-53.

4. Oteman N, Berger MY, Boomsma LJ, Wiersma TJ, Goudswaard AN. Summary of the practice guideline 'Children with fever' (Second Revision) from the Dutch College of General Practitioners. Ned Tijdschr Geneeskd. 2008;152:2781-6.

5. Schmitt BD. Fever phobia: misconceptions of parents about fevers. Am J Dis Child. 1980;134:176-81.

6. Crocetti M, Moghbeli N, Serwint J. Fever phobia revisited: have parental misconceptions about fever changed in 20 years? Pediatrics. 2001;107:1241-6.

7. Wallenstein MB, Schroeder AR, Hole MK, et al. Fever literacy and fever phobia. Clin Pediatr (Phila). 2013;52:254-9.

8. Thomas S, Vijaykumar C, Naik R, Moses PD, Antonisamy B. Comparative effectiveness of tepid sponging and antipyretic drug versus only antipyretic drug in the management of fever among children: a randomized controlled trial. Indian Pediatr. 2009;46: 133-6.

9. Agbolosu NB, Cuevas LE, Milligan P, et al. Efficacy of tepid sponging versus paracetamol in reducing temperature in febrile children. Ann Trop Paediatr. 1997;17:283-8.

10. Aksoylar S, Aksit S, Caglayan S, et al. Evaluation of sponging and antipyretic medication to reduce body temperature in febrile children. Acta Paediatr Jpn. 1997;39:215-7.

11. Hay AD, Redmond NM, Costelloe $\mathrm{C}$ et al. Paracetamol and ibuprofen for the treatment of fever in children: the PITCH randomised controlled trial. Health Technol Assess. 2009;13.

12. Lagerlov $P$, Helseth $S$, Holager T. Childhood illnesses and the use of paracetamol (acetaminophen): a qualitative study of parents' management of common childhood illnesses. Fam Pract. 2003;20:717-23.

13. Poirier MP, Collins EP, McGuire E. Fever phobia: a survey of caregivers of children seen in a pediatric emergency department. Clin Pediatr (Phila). 2010;49:530-4.

14. Langer T, Pfeifer M, Soenmez A, et al. Activation of the maternal caregiving system by childhood fever-a qualitative study of the experiences made by mothers with a German or a Turkish background in the care of their children. BMC Fam Pract. 2013;14:35.

15. Pereira GL, Tavares NU, Mengue SS, Pizzol TS. Therapeutic procedures and use of alternating antipyretic drugs for fever management in children. J Pediatr (Rio J). 2013;89:25-32.

16. Trautner BW, Caviness AC, Gerlacher GR, Demmler G, Macias CG. Prospective evaluation of the risk of serious bacterial infection in children who present to the emergency department with hyperpyrexia (temperature of 106 degrees $\mathrm{F}$ or higher). Pediatrics. 2006;118:34-40.

17. Alpert G, Hibbert E, Fleisher GR. Case-control study of hyperpyrexia in children. Pediatr Infect Dis J. 1990;9:161-3.

18. American Academy of Pediatrics, Steering Committee on Quality Improvement and Management SoFS. Febrile seizures: clinical practice guideline for the long-term management of the child with simple febrile seizures. Pediatrics. 2008;121:1281-6.

19. Offringa M, Newton R. Prophylactic drug management for febrile seizures in children. Cochrane Database Syst Rev. 2012;4: CD003031.

20. Strengell T, Uhari M, Tarkka R, et al. Antipyretic agents for preventing recurrences of febrile seizures: randomized controlled trial. Arch Pediatr Adolesc Med. 2009;163:799-804.

21. Chiappini E, Parretti A, Becherucci P, et al. Parental and medical knowledge and management of fever in Italian pre-school children. BMC Pediatr. 2012;12:97.

22. Chiappini E, Principi N, Longhi R, et al. Management of fever in children: summary of the Italian Pediatric Society guidelines. Clin Ther. 2009;31:1826-43. 
23. Goldman RD, Ko K, Linett LJ, Scolnik D. Antipyretic efficacy and safety of ibuprofen and acetaminophen in children. Ann Pharmacother. 2004;38:146-50.

24. Perrott DA, Piira T, Goodenough B, Champion GD. Efficacy and safety of acetaminophen vs ibuprofen for treating children's pain or fever: a meta-analysis. Arch Pediatr Adolesc Med. 2004;158:521-6.

25. Pierce CA, Voss B. Efficacy and safety of ibuprofen and acetaminophen in children and adults: a meta-analysis and qualitative review. Ann Pharmacother. 2010;44:489-506.

26. Hay AD, Costelloe C, Redmond NM, et al. Paracetamol plus ibuprofen for the treatment of fever in children $(\mathrm{PITCH})$ : randomised controlled trial. BMJ. 2008;337:a1302.

27. Autret E, Reboul-Marty J, Henry-Launois B, et al. Evaluation of ibuprofen versus aspirin and paracetamol on efficacy and comfort in children with fever. Eur J Clin Pharmacol. 1997;51:367-71.

28. Autret-Leca E, Gibb IA, Goulder MA. Ibuprofen versus paracetamol in pediatric fever: objective and subjective findings from a randomized, blinded study. Curr Med Res Opin. 2007;23: 2205-11.

29. Clark E, Plint AC, Correll R, Gaboury I, Passi B. A randomized, controlled trial of acetaminophen, ibuprofen, and codeine for acute pain relief in children with musculoskeletal trauma. Pediatrics. 2007;119:460-7.

30. Bradley RL, Ellis PE, Thomas P, et al. A randomized clinical trial comparing the efficacy of ibuprofen and paracetamol in the control of orthodontic pain. Am J Orthod Dentofacial Orthop. 2007;132:511-7.

31. Baygin O, Tuzuner T, Isik B, Kusgoz A, Tanriver M. Comparison of pre-emptive ibuprofen, paracetamol, and placebo administration in reducing post-operative pain in primary tooth extraction. Int J Paediatr Dent. 2011;21:306-13.

32. Hollinghurst $\mathrm{S}$, Redmond N, Costelloe $\mathrm{C}$, et al. Paracetamol plus ibuprofen for the treatment of fever in children (PITCH): economic evaluation of a randomised controlled trial. BMJ. 2008;337:a1490.

33. Southey ER, Soares-Weiser K, Kleijnen J. Systematic review and meta-analysis of the clinical safety and tolerability of ibuprofen compared with paracetamol in paediatric pain and fever. Curr Med Res Opin. 2009;25:2207-22.

34. van den Anker JN. Optimising the management of fever and pain in children. Int J Clin Pract Suppl. 2013;67:26-32.

35. Abdel-Tawab M, Zettl H, Schubert-Zsilavecz M. Nonsteroidal anti-inflammatory drugs: a critical review on current concepts applied to reduce gastrointestinal toxicity. Curr Med Chem. 2009;16:2042-63.

36. McIntyre J, Hull D. Comparing efficacy and tolerability of ibuprofen and paracetamol in fever. Arch Dis Child. 1996;74:164-7.

37. Huang JQ, Sridhar S, Hunt RH. Role of Helicobacter pylori infection and non-steroidal anti-inflammatory drugs in pepticulcer disease: a meta-analysis. Lancet. 2002;359:14-22.

38. Bjarnason I. Gastrointestinal safety of NSAIDs and over-thecounter analgesics. Int J Clin Pract Suppl. 2013;67:37-42.

39. Lesko SM, Mitchell AA. An assessment of the safety of pediatric ibuprofen. A practitioner-based randomized clinical trial. JAMA. 1995;273:929-33.

40. Grimaldi-Bensouda L, Abenhaim L, Michaud L, et al. Clinical features and risk factors for upper gastrointestinal bleeding in children: a case-crossover study. Eur J Clin Pharmacol. 2010;66:831-7.

41. Bianciotto M, Chiappini E, Raffaldi I, et al. Drug use and upper gastrointestinal complications in children: a case-control study. Arch Dis Child. 2013;98:218-21.

42. McClain CJ, Price S, Barve S, Devalarja R, Shedlofsky S. Acetaminophen hepatotoxicity: an update. Curr Gastroenterol Rep. 1999;1:42-9.

43. John CM, Shukla R, Jones CA. Using non-steroidal anti-inflammatory drugs (NSAIDs) in volume depleted children can precipitate acute renal failure. BMJ Case Rep. 2008;2009(bcr12): 1318.

44. Rainsford KD, Bjarnason I. NSAIDs: take with food or after fasting? J Pharm Pharmacol. 2012;64:465-9.

45. de Weck AL, Gamboa PM, Esparza R, Sanz ML. Hypersensitivity to aspirin and other nonsteroidal anti-inflammatory drugs (NSAIDs). Curr Pharm Des. 2006;12:3347-58.

46. Jenkins C, Costello J, Hodge L. Systematic review of prevalence of aspirin induced asthma and its implications for clinical practice. BMJ. 2004;328:434.

47. Kanabar D, Dale S, Rawat M. A review of ibuprofen and acetaminophen use in febrile children and the occurrence of asthmarelated symptoms. Clin Ther. 2007;29:2716-23.

48. Debley JS, Carter ER, Gibson RL, Rosenfeld M, Redding GJ. The prevalence of ibuprofen-sensitive asthma in children: a randomized controlled bronchoprovocation challenge study. J Pediatr. 2005; 147:233-8.

49. Lesko SM, Louik C, Vezina RM, Mitchell AA. Asthma morbidity after the short-term use of ibuprofen in children. Pediatrics. 2002;109:E20.

50. McBride JT. The association of acetaminophen and asthma prevalence and severity. Pediatrics. 2011;128:1181-5.

51. Eneli I, Sadri K, Camargo C Jr, Barr RG. Acetaminophen and the risk of asthma: the epidemiologic and pathophysiologic evidence. Chest. 2005;127:604-12.

52. Beasley RW, Clayton TO, Crane J, et al. Acetaminophen use and risk of asthma, rhinoconjunctivitis, and eczema in adolescents: International Study of Asthma and Allergies in Childhood Phase Three. Am J Respir Crit Care Med. 2011; 183:171-8.

53. Kreiner-Moller E, Sevelsted A, Vissing NH, Schoos AM, Bisgaard $\mathrm{H}$. Infant acetaminophen use associates with early asthmatic symptoms independently of respiratory tract infections: the Copenhagen Prospective Study on Asthma in Childhood 2000 (COPSAC(2000)) cohort. J Allergy Clin Immunol. 2012;130: 1434-6.

54. Holgate ST. The acetaminophen enigma in asthma. Am J Respir Crit Care Med. 2011;183:147-8.

55. Musu M, Finco G, Antonucci R, et al. Acute nephrotoxicity of NSAID from the foetus to the adult. Eur Rev Med Pharmacol Sci. 2011;15:1461-72.

56. Whelton A. Nephrotoxicity of nonsteroidal anti-inflammatory drugs: physiologic foundations and clinical implications. Am J Med. 1999;106:13S-24S.

57. Lesko SM, Mitchell AA. The safety of acetaminophen and ibuprofen among children younger than two years old. Pediatrics. 1999; 104:e39.

58. Lesko SM, Mitchell AA. Renal function after short-term ibuprofen use in infants and children. Pediatrics. 1997;100:954-7.

59. Ashraf E, Ford L, Geetha R, Cooper S. Safety profile of ibuprofen suspension in young children. Inflammopharmacology. 1999;7: 219-25.

60. Krause I, Cleper R, Eisenstein B, Davidovits M. Acute renal failure, associated with non-steroidal anti-inflammatory drugs in healthy children. Pediatr Nephrol. 2005;20:1295-8.

61. Moghal NE, Hegde S, Eastham KM. Ibuprofen and acute renal failure in a toddler. Arch Dis Child. 2004;89:276-7.

62. Ulinski T, Guigonis V, Dunan O, Bensman A. Acute renal failure after treatment with non-steroidal anti-inflammatory drugs. Eur J Pediatr. 2004;163:148-50.

63. van Ierland Y, Elshout G, Moll HA, et al. Use of alarm features in referral of febrile children to the emergency department: an observational study. Br J Gen Pract. 2014;64:e1-9.

64. Misurac JM, Knoderer CA, Leiser JD, et al. Nonsteroidal antiinflammatory drugs are an important cause of acute kidney injury in children. J Pediatr. 2013;162:1153-9. 
65. Iorio ML, Cheerharan M, Kaufman SS, Reece-Stremtan S, Boyajian M. Acute liver failure following cleft palate repair: a case of therapeutic acetaminophen toxicity. Cleft Palate Craniofac J. 2013;50:747-50.

66. Savino F, Lupica MM, Tarasco V, et al. Fulminant hepatitis after 10 days of acetaminophen treatment at recommended dosage in an infant. Pediatrics. 2011;127:e494-7.

67. Ferrajolo C, Capuano A, Verhamme KM, et al. Drug-induced hepatic injury in children: a case/non-case study of suspected adverse drug reactions in VigiBase. $\mathrm{Br} \mathrm{J}$ Clin Pharmacol. 2010;70:721-8.

68. Mahadevan SB, McKiernan PJ, Davies P, Kelly DA. Paracetamol induced hepatotoxicity. Arch Dis Child. 2013;91:598-603.

69. Hon KL, Leung AK. Be careful, mom and doc: hepatotoxicity associated with prescribed medications in young infants. Int $\mathbf{J}$ Pediatr. 2009;2009:673269.

70. Kubic A, Burda AM, Bockewitz E, Wahl M. Hepatotoxicity in an infant following supratherapeutic dosing of acetaminophen for twenty-four hours. Semin Diagn Pathol. 2009;26:7-9.

71. Eyers S, Fingleton J, Perrin K, Beasley R. Proposed MHRA changes to UK children's paracetamol dosing recommendations: modelling study. J R Soc Med. 2012;105:263-9.

72. Eyers S, Fingleton J, Eastwood A, Perrin K, Beasley R. British National Formulary for Children: the risk of inappropriate paracetamol prescribing. Arch Dis Child. 2012;97:279-82.

73. Australian Government Department of Health TGA. Over-thecounter medicines. 2013. http://www.tga.gov.au/industry/otc. htm\#.U3HyFPldU2s. Accessed May 2014.

74. Volans G, Monaghan J, Colbridge M. Ibuprofen overdose. Int J Clin Pract Suppl. 2003;57:54-60.

75. Hall AH, Smolinske SC, Conrad FL, et al. Ibuprofen overdose: 126 cases. Ann Emerg Med. 1986;15:1308-13.

76. Argentieri J, Morrone K, Pollack Y. Acetaminophen and ibuprofen overdosage. Pediatr Rev. 2012;33:188-9.

77. Varicella, herpes zoster and nonsteroidal anti-inflammatory drugs: serious cutaneous complications. Prescrire Int. 2010;19:72-3.

78. Kramer LC, Richards PA, Thompson AM, Harper DP, Fairchok MP. Alternating antipyretics: antipyretic efficacy of acetaminophen versus acetaminophen alternated with ibuprofen in children. Clin Pediatr (Phila). 2008;47:907-11.
79. Paul IM, Sturgis SA, Yang C, et al. Efficacy of standard doses of ibuprofen alone, alternating, and combined with acetaminophen for the treatment of febrile children. Clin Ther. 2010;32:2433-40.

80. Purssell E. Systematic review of studies comparing combined treatment with paracetamol and ibuprofen, with either drug alone. Arch Dis Child. 2011;96:1175-9.

81. Pereira GL, Dagostini JM, Pizzol TS. Alternating antipyretics in the treatment of fever in children: a systematic review of randomized clinical trials. J Pediatr (Rio J). 2012;88:289-96.

82. Saphyakhajon P, Greene G. Alternating acetaminophen and ibuprofen in children may cause parental confusion and is dangerous. Arch Pediatr Adolesc Med. 2006;160:757-8.

83. Schmitt BD. Concerns over alternating acetaminophen and ibuprofen for fever. Arch Pediatr Adolesc Med. 2006;160:757-8.

84. Moore RA, Straube S, Paine J, Derry S, McQuay HJ. Minimum efficacy criteria for comparisons between treatments using individual patient meta-analysis of acute pain trials: examples of etoricoxib, paracetamol, ibuprofen, and ibuprofen/paracetamol combinations after third molar extraction. Pain. 2011;152:982-9.

85. Mullins ME, Empey M, Jaramillo D, et al. A prospective randomized study to evaluate the antipyretic effect of the combination of acetaminophen and ibuprofen in neurological ICU patients. Neurocrit Care. 2011;15:375-8.

86. de Vries F, Setakis E, van Staa TP. Concomitant use of ibuprofen and paracetamol and the risk of major clinical safety outcomes. Br J Clin Pharmacol. 2010;70:429-38.

87. Purssell E, While AE. Does the use of antipyretics in children who have acute infections prolong febrile illness? A systematic review and meta-analysis. J Pediatr. 2013;163:822-7.

88. Mahadevan SB, McKiernan PJ, Davies P, Kelly DA. Paracetamol induced hepatotoxicity. Arch Dis Child. 2006;91:598-603.

89. Medicines and Healthcare products Regulatory Agency (MHRA). MHRA UK Public Assessment Report: Liquid paracetamol for children: revised UK dosing instructions have been introduced. 2011. http://www.mhra.gov.uk/home/groups/comms-ic/documents/ websiteresources/con134921.pdf. Accessed May 2014.

90. National Institute for Health and Care Excellence (NICE). Clinical Knowledge Summaries: Feverish children-management. 2013. http://cks.nice.org.uk/feverish-children-management\#! scenarioclarification. Accessed May 2014. 